\title{
Calorie Restriction in Adulthood Reduces Hepatic Disorders Induced by Transient Postnatal Overfeeding in Mice
}

\author{
Catherine Yzydorczyk ${ }^{1} * \mathbb{D}$, Na Li ${ }^{2}$, Eve Rigal ${ }^{2}$, Hassib Chehade ${ }^{1}$, Dolores Mosig ${ }^{1}$, \\ Jean Baptiste Armengaud ${ }^{1}$, Thibaud. Rolle ${ }^{1}$, Anithan Krishnasamy ${ }^{1}$, Eulalia Orozco ${ }^{1}$, \\ Benazir Siddeek ${ }^{1}$, Christian Juvet ${ }^{1}$, Catherine Vergely ${ }^{2,+}$ and Umberto Simeoni ${ }^{1,+}$ \\ 1 DOHaD Laboratory, Woman-Mother-Child Department, Division of Pediatrics, Centre Hospitalier \\ Universitaire Vaudois and University of Lausanne, 1011 Lausanne, Switzerland; \\ hassib.chehade@chuv.ch (H.C.); dolores.mosig@me.com (D.M.); jean-baptiste.armengaud@chuv.ch (J.B.A.); \\ Rotib7@gmail.com (T.R.); anithan.krishnasamy@gmail.com (A.K.); eulalia_of@hotmail.com (E.O.); \\ benazir.siddeek@chuv.ch (B.S.); christian.juvet@chuv.ch (C.J.); umberto.simeoni@chuv.ch (U.S.) \\ 2 Equipe Physiopathologie et Epidémiologie Cérébro-Cardiovasculaires (PEC2, EA7460), UFR Sciences de \\ Santé, Université de Bourgogne Franche-Comté, 21000 Dijon, France; na.li@unil.ch (N.L.); \\ eve.rigal@u-bourgogne.fr (E.R.); cvergely@u-bourgogne.fr (C.V.) \\ * Correspondence: catherine.yzydorczyk@chuv.ch; Tel.: +41-(0)21-314-32-19 \\ + Whose contributions are equal.
}

Received: 9 October 2019; Accepted: 14 November 2019; Published: 16 November 2019

\begin{abstract}
Impaired early nutrition influences the risk of developing metabolic disorders in later life. We observed that transient postnatal overfeeding $(\mathrm{OF})$ in mice induces long-term hepatic alterations, characterized by microsteatosis, fibrosis associated with oxidative stress (OS), and stress-induced premature senescence (SIPS). In this study, we investigated whether such changes can be reversed by moderate calorie restriction (CR). C57BL/6 male mice pups were maintained during lactation in litters adjusted to nine pups in the normal feeding (NF) group and three pups in the transient postnatal OF group. At six months of age, adult mice from the NF and OF groups were randomly assigned to an ad libitum diet or CR (daily energy supply reduced by $20 \%$ ) for one month. In each group, at the age of seven months, analysis of liver structure, liver markers of OS (superoxide anion, antioxidant defenses), and SIPS (lipofuscin, p53, p21, p16, pRb/Rb, Acp53, sirtuin-1) were performed. CR in the OF group reduced microsteatosis, decreased levels of superoxide anion, and increased protein expression of catalase and superoxide dismutase. Moreover, CR decreased lipofuscin staining, p21, $\mathrm{p} 53$, Acp53, and $\mathrm{p} 16$ but increased $\mathrm{pRb} / \mathrm{Rb}$ and sirtuin-1 protein expression. CR did not affect the NF group. These results suggest that $\mathrm{CR}$ reduces hepatic disorders induced by $\mathrm{OF}$.
\end{abstract}

Keywords: liver; developmental programming; stress-induced premature senescence; oxidative stress; reversibility; $\mathrm{DOHaD}$

\section{Introduction}

In recent years, the prevalence of obesity has dramatically increased worldwide and is considered a major global health problem. Notably, obesity in children/adolescents is particularly worrying. In 40 years, the number of school-age children and adolescents with obesity has greatly increased from 11 million to 124 million [1]. Adverse health consequences of obesity are observed in many western populations and include higher blood pressure, obesity, glucose intolerance, dyslipidemia, decreased insulin sensitivity, and type 2 diabetes, which are components of metabolic syndrome (MetS) [2]. Nonalcoholic fatty liver disease (NAFLD), which is the major prevalent acquired chronic liver disease 
in developed countries [3], is considered a hepatic manifestation of MetS [4]. Impaired nutritional conditions during early development, such as maternal and paternal undernutrition or overnutrition, maternal dietary imbalance during pregnancy, and altered early postnatal nutrition, are associated with the developmental programming of cardiometabolic diseases in adulthood [2].

Such clinical and epidemiological observations have been reproduced in animal models. In rodents, reduced litter size after birth decreases competition for milk during the lactation period and therefore induces overnutrition in the early postnatal period. At weaning, increased body weight and fat content have been observed [5]. Furthermore, in adulthood, early postnatal overfeeding (OF) induces metabolic and cardiovascular alterations [6-11].

The liver plays a key role in lipid and glucose metabolism. Liver function and structure are particularly sensitive to oxidative stress (OS)-related damage that can lead to hepatocyte dysfunction, notably accelerated senescence, which is involved in acute and chronic liver disease [12].

We have previously observed that transient postnatal OF during the suckling period in mice led to liver microsteatosis and fibrosis in adulthood, and this outcome was associated with OS and stress-induced premature senescence (SIPS) [13]. Calorie restriction (CR), as a potential preventive strategy for metabolic disorders, has received considerable interest. CR, which can be defined as a decrease in energy intake without malnutrition, has been shown to be protective against liver diseases in human studies $[14,15]$ and to improve health span, delay cardiac aging, and improve cardiometabolic health [16,17]. In animal models, CR reduced NAFLD in $\mathrm{db} / \mathrm{db}$ mice [18] and middle-aged C57BL/6J mice [19] and reversed glucose metabolism and cardiac dysfunctions induced by transient postnatal OF [11]. A proposed explanation for these beneficial effects is that CR results in a mildly stressful situation that elicits a survival response, notably by modulating sirtuin-1 (Sirt-1) activity and expression [20], which helps the organism survive in adverse situations by altering the metabolism and increasing defenses against the causes of aging, whatever the origins may be [21].

However, whether CR in adulthood can reverse hepatic alterations programmed by altered early nutrition is still unknown. In this study, we explored whether moderate CR $(20 \%)$ over a short period (one month) in adulthood can prevent hepatic structure alterations, liver OS, and SIPS induced by transient postnatal OF in a mouse model.

\section{Materials and Methods}

\subsection{Animal Model}

Investigations were performed in accordance with the Directive 2010/63/EU of the European Parliament and the Guidelines for the Care and Use of Laboratory Animals published by the U.S. National Institutes of Health (NIH Publication No. 85-23, revised 1996). The Comité d'Ethique de l'Experimentation Animale, Université de Bourgogne-Franche-Comté, Dijon, France acted as the institutional review board (protocol agreement number: 00412.03) and specifically approved this study.

In this study, we used the same cohort of animals that was previously described by Li et al. [11]. Briefly, adult female C57BL/6 mice (Charles River, L'Arbresle, France) at six weeks of age were individually housed. After one week of adaptation, they were mated overnight with males at a proportion of 2:1. On the third day of life, male pups were randomly distributed among mothers to achieve cross fostering. Litter sizes were adjusted to either nine male pups in the normal feeding (NF) group or three male pups in the postnatal overfeeding $(\mathrm{OF})$ group during the lactation period (three weeks). Each litter included pups from one to six different dams to increase genetic variability within the litters. After weaning, the mice in both groups had free access to a standard diet (A04, SAFE Diets Augy, France) and water.

At six months of life, mice were randomly assigned for one month to either an ad libitum diet (NF and OF groups) or to a CR diet induced by a reduction in daily food supply of $20 \%$ (based on the food intake of each group), which led to the establishment of the NFCR and OFCR groups. To perform all the 
experiments presented in this study, two consecutive series of reproductions were used, corresponding to 12 different litters.

Only males from each group (NF $(n=5-6)$, OF $(n=5-6), \operatorname{NFCR}(n=4-5)$, and OFCR $(n=4-5))$ were studied at seven months of age. After $6 \mathrm{~h}$ of fasting, mice were sacrificed, and the livers were then harvested and immediately frozen in nitrogen for western blot analyses or fixed in formol for histological analyses.

\subsection{Evaluation of Hepatic Structure by Histological Analysis}

At seven months of life, the livers from the NF $(n=5), \operatorname{OF}(n=5), \operatorname{NFCR}(n=5)$ and OFCR $(n=5)$ groups were rapidly removed and fixed in formol as previously described [13]. Equatorial cross-sections were paraffin-embedded and stained with hematoxylin and eosin (H/E) for hepatic structure evaluation and with Masson's Trichrome to evaluate hepatic fibrosis. For all histological analyses, the slides were observed blindly by the same experimenter (C.Y), and three images were captured for each animal. A pathologist (Prof. C. Sempoux) confirmed the histological observations. Hepatic fibrosis was quantified using ImageJ 1.50b (Java 1.8.0_60, National Institutes of Health, MD, USA) (http://rsbweb.nih.gov/ij), as previously described [13].

\subsection{Detection of Superoxide Anion $\left(\mathrm{O}_{2}^{\bullet-}\right)$ by Chemiluminescence}

Liver $\mathrm{O}_{2}{ }^{\bullet-}$ production was evaluated at seven months of life in the NF $(n=5)$, OF $(n=5)$, NFCR $(n=5)$, and OFCR $(n=5)$ groups using oxidative fluorescent dye hydroethidine $(2 \mu \mathrm{M}$, Sigma-Aldrich) [22,23] as previously described [13]. Briefly, liver sections were stained with hydroethidine by incubating the sections in a light-protected humidified chamber at $37^{\circ} \mathrm{C}$ for $30 \mathrm{~min}$. The sections were rinsed with phosphate-buffered saline (PBS) and mounted using Fluoromount-G mounting medium with 4'6-diamidino-2-phenylindole (DAPI; Interchim, France). The slides were observed blindly by the same experimenter (C.Y), and images were obtained using a laser scanning confocal microscope (Leica SP5) equipped with an argon laser. At least four hepatic sections were assessed per animal with a 514-nm long-pass filter and were evaluated with ImageJ software [13].

\subsection{Detection of Oxidative DNA Double-Strand Break}

As previously described [13], liver sections from 7-month-old mice from the NF $(n=5), \mathrm{OF}(n=5)$, NFCR $(n=5)$ and OFCR $(n=5)$ groups were stained with 53BP-1 (1/100, Abcam, \#ab21083) overnight at $4{ }^{\circ} \mathrm{C}$. The sections were then washed with PBS and incubated for two hours with Alexa Fluor-488-conjugated donkey anti-rabbit IgG (1/200, Abcam, \#ab150073). The sections were then rinsed with PBS and mounted using Fluoromount-G mounting medium with DAPI. A negative control was obtained by incubation only with secondary antibody. The slides were observed blindly using a fluorescence microscope (Nikon, Eclipse Ti2 Series) by the same experimenter (C.Y), and at least four hepatic sections were assessed per animal using ImageJ software [13].

\subsection{Detection of Liver Senescence by Histological Staining}

A marker of SIPS [24], lipofuscin, was identified by diastase periodic acid Schiff (d-PAS) resistance and Fontana Masson and Sudan Black B (SBB) staining of livers from NF $(n=5)$, OF $(n=5)$, NFCR $(n=5)$, and OFCR $(n=5)$ groups. For all histological analyses, three images were captured for each animal. Lipofuscin staining was quantified using ImageJ software. A quantitative analysis was performed blindly by a single experimenter (C. Y), as previously described [13].

\subsection{Western Blotting}

Liver proteins from the NF $(n=5)$, OF $(n=5)$, NFCR $(n=4)$ and OFCR $(n=4-6)$ groups were extracted at seven months of life (from the medial lobe of the snap-frozen livers) using radioimmunoprecipitation assay buffer (RIPA) buffer as previously reported [13]. Proteins were 
quantified (Pierce BCA Protein Assay Kit, Thermo Scientific, Rockford, IL, USA) and western blotting was performed. Denatured liver proteins $(30 \mu \mathrm{g})$ from the specific groups were separated using gradient gel (NuPAGE $4-12 \%$ Bis-Tris gel, Thermo Scientific) and transferred overnight at $4{ }^{\circ} \mathrm{C}$. All primary antibody incubations were performed in blocking buffer tris-buffered saline ((TBS)-Tween $2 \%$-bovine serum albumin (BSA) $3 \%$ ) overnight at $4{ }^{\circ} \mathrm{C}$. Antibodies (Cell Signaling 1/1000e) against catalase (Cat; \#14097), Sirt-1 (\#9475), retinoblastoma tumor suppressor protein ( $\mathrm{Rb}, \# 9313)$ and phospho- $\mathrm{Rb}(\mathrm{pRb}$, Ser807/811, \#8516); p53 (\#2524) and acetyl-p53 (Lys379, \#2570); p21 WAF, CDKN2A/p16 ${ }^{\mathrm{INK4a}}$, and Cu/Zn superoxide dismutase (Sod) (Abcam, 1/1000e, \#ab188224; \# ab201980 and \#ab13498, respectively); and alpha smooth muscle actin (a-SMA, Sigma-Aldrich, 1/1000e, \#A5228) were purchased. Incubations were performed in blocking buffer at room temperature for one hour with anti-mouse or anti-rabbit secondary antibodies (1/2000; Cell Signaling, \#7076 and \#7074, respectively). The antibodies were visualized using enhanced chemiluminescence western blotting substrate (Thermo Scientific). To detect specific bands, a G-BOX Imaging System (GeneSys, Syngene, Cambridge, UK) or a photographic film (CL-XPosureTM Film, Thermo Scientific) was used, and the optical density of each band was scanned and measured using specific software (GeneTools 4.03.05.0, Cambridge, England). Full-length western blots are presented.

\subsection{Statistical Analyses}

For each parameter, the mean \pm standard deviation (SD) was used for comparisons between groups. Given the small sample size, the means of each parameter of interest were compared using a nonparametric Mann-Whitney $U$ test. The significance level was set at $p<0.05$. Statistical analyses were performed and graphics were created using GraphPad Prism version 8.3.0 (La Jolla, CA, USA).

\section{Results}

\subsection{Effect of Calorie Restriction on Liver Structure}

Hepatic steatosis was evaluated by $\mathrm{H} / \mathrm{E}$, and hepatic fibrosis was explored with Masson's Trichrome staining and with the measurement of $\alpha$-SMA protein expression in the NF, NFCR, OF, and OFCR groups.

In the livers from the OFCR group compared to those of the OF group, we observed, using H/E, a decreased wispy cleared cytoplasm indicating reduced microsteatosis (Figure 1A). In the livers from the NFCR and NF groups, we observed no lipid droplet accumulation via H/E staining (Figure 1A).

With Masson's Trichrome staining, we observed that the mean percentage of hepatic fibrotic area was not significantly different between the livers from the OFCR group and the livers from the OF group (OFCR vs. OF (arbitrary units (A.U.) \pm SD) $7.98 \pm 1.24$ vs. $9.04 \pm 0.55 ; p>0.05$ ) (Figure 1B,C). Additionally, we observed no significant difference in $\alpha$-SMA protein expression between the OFCR and OF groups (OFCR vs. OF (A.U. \pm SD) $0.66 \pm 0.07$ vs. $0.85 \pm 0.09 ; p>0.05$ ) (Figure 1D,E). No difference was observed between the livers from the NFCR group and those from the NF group (NFCR vs. NF (A.U. \pm SD) $0.66 \pm 0.17$ vs. $0.70 \pm 0.20 ; p<0.001$; Figure 1B,C).

\subsection{Effect of Calorie Restriction on Oxidative Stress in Hepatic Tissue}

Liver OS was investigated by superoxide anion production (hydroethidine) quantification and catalase and $\mathrm{Cu} / \mathrm{Zn}$ Sod protein expression measurement. The livers from the OFCR group, compared to $\mathrm{OF}$ group, displayed significantly decreased $\mathrm{O}_{2}{ }^{\bullet-}$ production (OFCR vs. OF (A.U. \pm SD) $4.75 \pm 0.84$ vs. $21.45 \pm 1.18 ; p<0.001$ ) (Figure $2 \mathrm{~A}, \mathrm{~B}$ ).

We observed an increase in $\mathrm{Cu} / \mathrm{Zn}$ Sod $(+564 \% ; p<0.05)$ (Figure $2 \mathrm{C}, \mathrm{D})$ and catalase $(+38 \%$; $p<0.05$ ) (Figure 2E,F) protein expression in the livers from the OFCR group compared to that in the livers of the OF group. 
No difference was observed between the NFCR and NF groups in regard to $\mathrm{O}_{2}{ }^{\bullet-}$ production (NFCR vs. NF (A.U. \pm SD) $4.83 \pm 0.79$ vs. $5.33 \pm 1.12 ; p>0.05$ ) (Figure $2 \mathrm{~A}, \mathrm{~B}$ ) or in regard to Cu/Zn Sod (Figure 2G,H) and catalase (Figure 2I,J) protein expression.
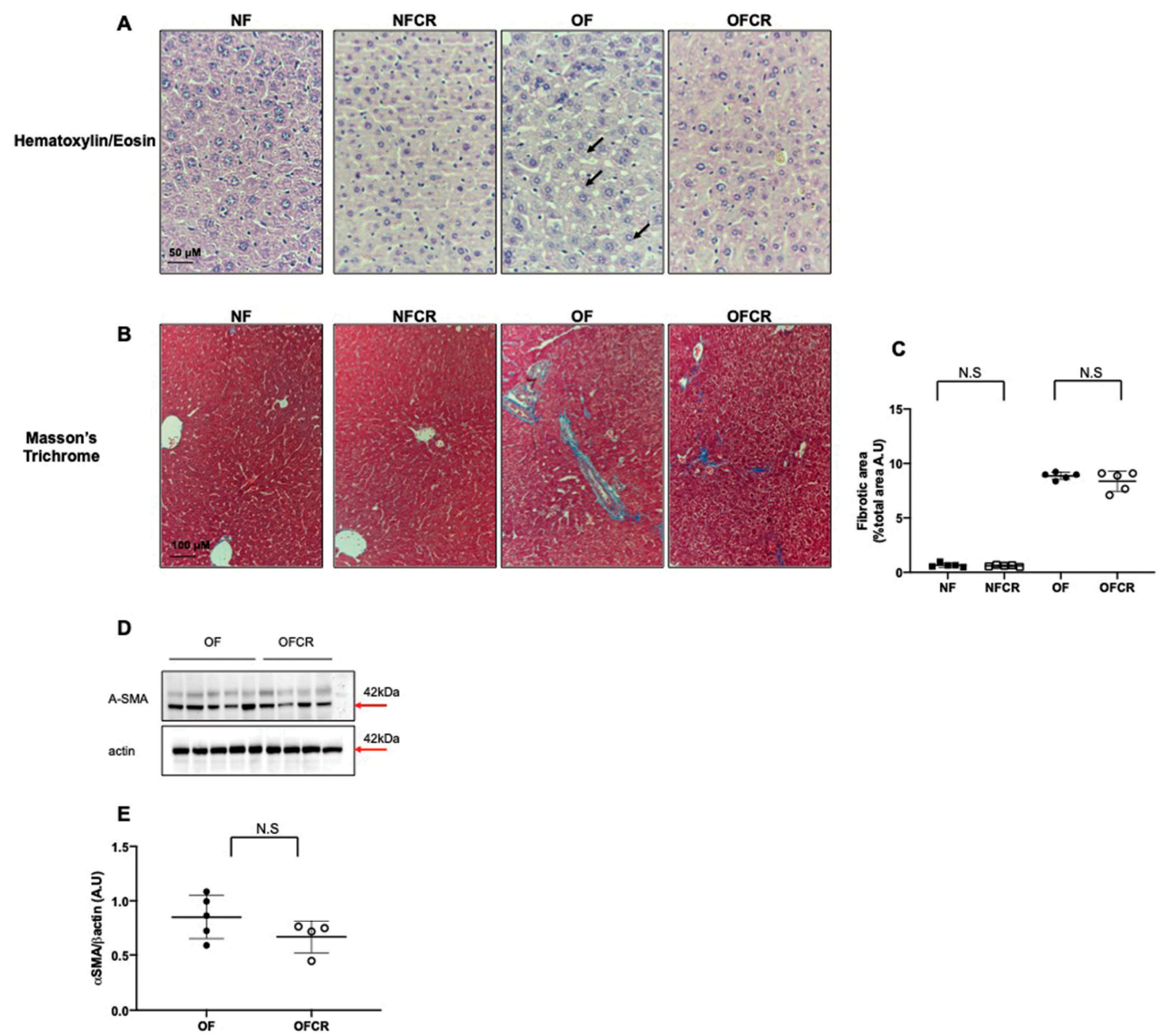

Figure 1. Hepatic structure of the animals in the normal feeding (NF), normal feeding calorie restriction (NFCR), overfeeding (OF), and overfeeding calorie restriction (OFCR) groups at seven months of age. Basic liver histology was evaluated using hematoxylin (nuclear localization) and eosin (cytoplasmic localization) staining (A) in the NF, NFCR, OF, and OFCR groups at $40 \times$ to evaluate steatosis. The arrows indicate slight microsteatosis in the OF group. Hepatic fibrosis was evaluated with Masson's Trichrome staining (B) in the NF, NFCR, OF and OFCR groups at 20× and was quantified using ImageJ (C). N.S: nonsignificant, $p>0.05$. These pictures are representative images from $n=5$ animals/group. In (D,E), alpha-SMA protein expression was measured using western blot in the OF and OFCR groups. Values are reported as the mean \pm SD; N.S nonsignificant, $p>0.05 ; n=5-4$. animals/group.

\subsection{Effect of Calorie Restriction on DNA Double-Strand Break in Hepatic Tissue}

The DNA double-strand breaks were explored using 53BP-1 staining. The livers from the OFCR group displayed no significant decrease in 53BP-1 staining compared to those from the OF group (OFCR vs. OF (arbitrary units \pm SD) $21.41 \pm 2.88$ vs. $20.62 \pm 4.88 ; p>0.05$ ) (Figure 3A,B).

No difference was observed between the NFCR and NF groups concerning 53BP-1 staining (NFCR vs. NF (A.U. \pm SD) $16.21 \pm 2.07$ vs. $16.55 \pm 1.05 ; p>0.05)$ (Figure 3A,B). 


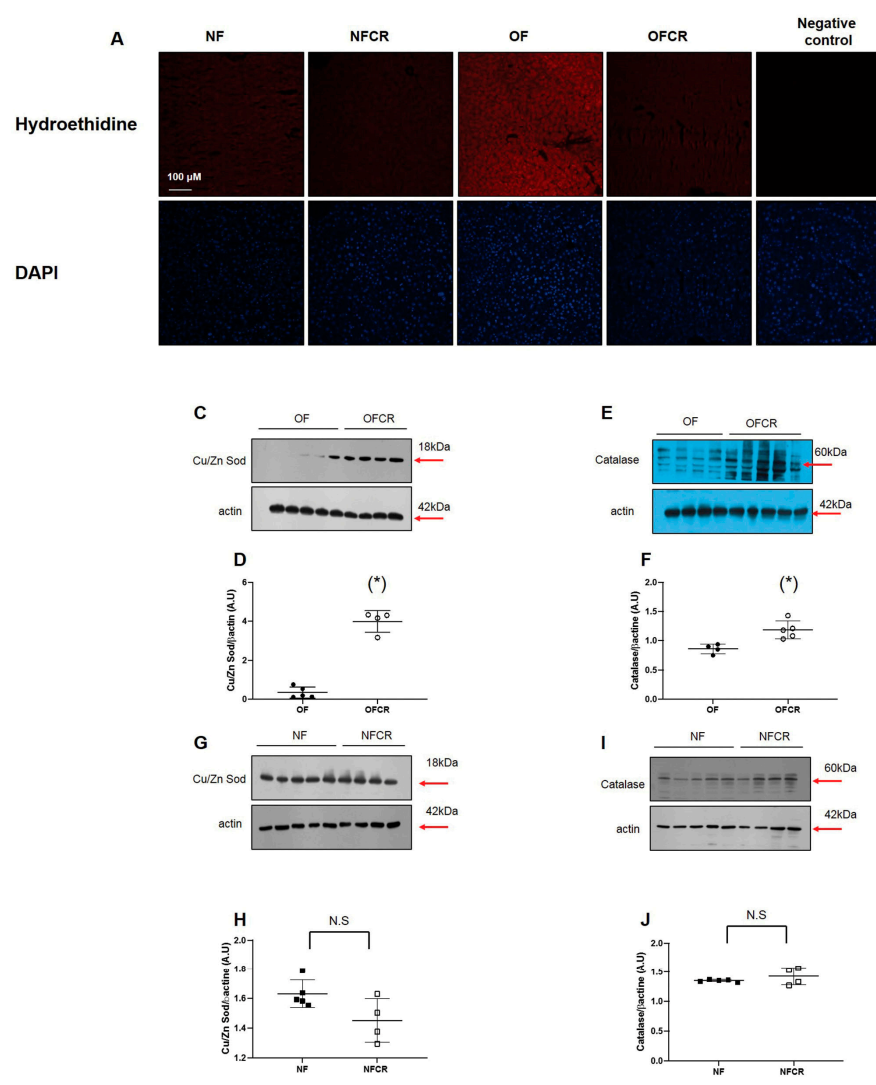

Figure 2. Liver superoxide anion production and antioxidant defense protein expression in the NF, NFCR, OF, and OFCR groups at seven months of age. Superoxide anion production was measured by hydroethidine staining (A) at the same magnification (20×) in the NF, NFCR, OF, and OFCR groups. Nuclei were counterstained with DAPI. A negative control was included. Hydroethidine fluorescence intensity was quantified using ImageJ (B). ${ }^{* * *} p<0.001$, N.S: nonsignificant, $p>0.05$. These pictures are representative images from $n=5$ animals/group. $\mathrm{Cu} / \mathrm{Zn}$ superoxide dismutase $(\mathrm{Cu} / \mathrm{Zn}$ Sod) $(\mathbf{C}, \mathbf{D})$ and catalase $(\mathrm{E}, \mathrm{F})$ protein expression levels were measured by western blot in the OF and OFCR groups. $\mathrm{Cu} / \mathrm{Zn}$ superoxide dismutase $(\mathrm{Cu} / \mathrm{Zn} \mathrm{Sod})(\mathbf{G}, \mathbf{H})$ and catalase $(\mathbf{I}, \mathbf{J})$ protein expression levels were also measured by western blot and in the NF and NFCR groups. Values are reported as the mean \pm SD; $\left(^{*}\right)$ $p<0.05 ;$ N.S: nonsignificant, $p>0.05 ; n=5-4$. animals/group.

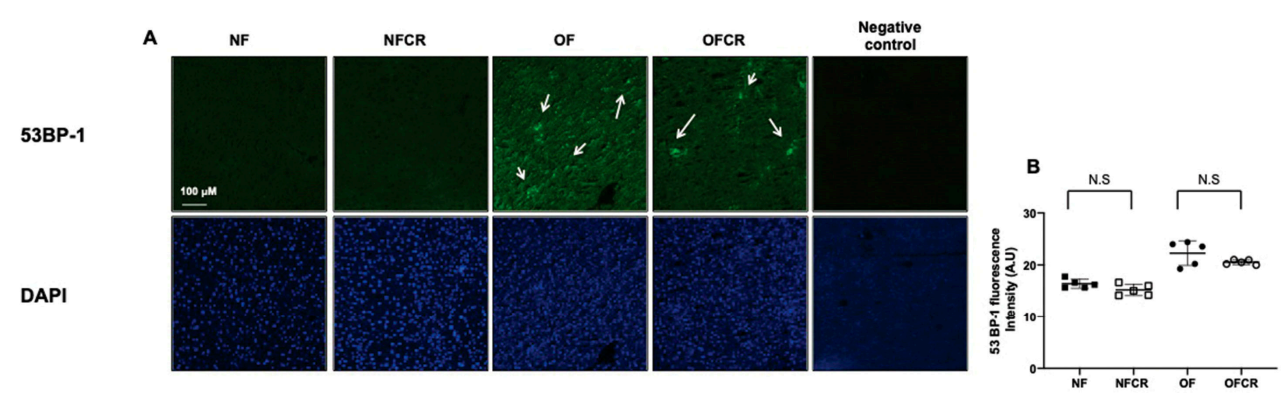

Figure 3. Liver DNA double-strand break evaluation in the NF, NFCR, OF, and OFCR groups at seven months of age. DNA double-strand breaks were evaluated by 53BP-1 staining at the same magnification $(20 \times)$ in the NF, NFCR, OF, and OFCR groups (A). The presence of a DNA double stand break was observed in the OF and OFCR groups (arrows). Nuclei were counterstained with DAPI. A negative control was included. These pictures are representative images from $n=5$ animals/group. 53BP-1 fluorescence intensity was quantified using ImageJ (B), N.S: nonsignificant, $p>0.05$. 


\subsection{Effect of Calorie Restriction on Histological Detection of Senescence}

The presence of lipofuscin deposits was detected using d-PAS resistance, SBB and Fontana Masson staining. The livers from the OFCR group, compared to OF group, displayed decreased d-PAS (OFCR vs. OF (A.U. \pm SD) $0.48 \pm 0.11$ vs. $8.22 \pm 0.94 ; p<0.001$ ) (Figure 4 A,B), SBB (OFCR vs. OF (A.U. \pm SD) $0.50 \pm 0.13$ vs. $2.88 \pm 0.15 ; p<0.001$ ) (Figure 4 C,D) and Fontana Masson (OFCR vs. OF (A.U. \pm SD) $1.89 \pm 0.20$ vs. $6.92 \pm 0.22 ; p<0.001$ ) (Figure $4 \mathrm{E}, \mathrm{F}$ ) staining.

No difference between the livers of the NFCR group and those of the NF group was observed concerning d-PAS (NFCR vs. NF (A.U. \pm SD) $0.47 \pm 0.13$ vs. $0.57 \pm 0.13 ; p>0.05$ ) (Figure $4 \mathrm{~A}, \mathrm{~B}$ ), SBB (NFCR vs. NF (A.U. \pm SD) $0.47 \pm 0.11$ vs. $0.57 \pm 0.13 ; p>0.05$ ) (Figure 4 C,D), or Fontana Masson (NFCR vs. NF (A.U. \pm SD) $1.69 \pm 0.10$ vs. $1.80 \pm 0.06 ; p>0.05$ ) (Figure $4 \mathrm{E}, \mathrm{F}$ ) staining.

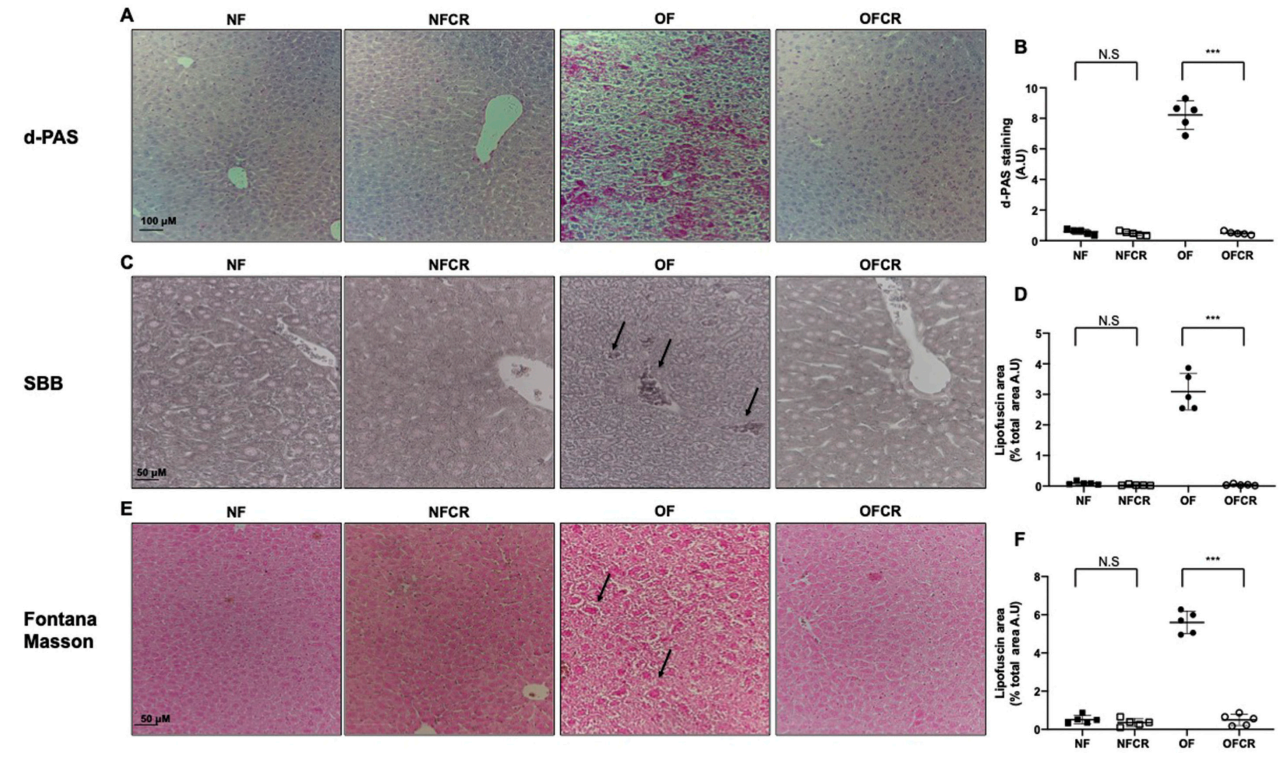

Figure 4. Lipofuscin accumulation using diastase periodic-Schiff (d-PAS), Sudan black B (SBB) and Fontana Masson staining in the livers of the animals in the NF, NFCR, OF and OFCR groups at 7 seven months of age. d-PAS staining (A) was evaluated in the NF, NFCR, OF and OFCR groups at 20×. d-PAS staining was quantified using ImageJ (B), ${ }^{* * *} p<0.001$; N.S: nonsignificant, $p>0.05$. SBB staining (C) (arrow in the OF group) was evaluated in the NF, NFCR, OF and OFCR groups at 40×. SBB staining was quantified using ImageJ (D), ${ }^{* * *} p<0.001 ;$ N.S: nonsignificant, $p>0.05$. Fontana Masson staining (E) (arrow in OF group) was evaluated in the NF, NFCR, OF and OFCR groups at 40×. Fontana Masson staining was quantified using Image $(\mathbf{F}){ }^{* * *} p<0.001$; N. S: nonsignificant, $p>0.05$. These pictures are representative images from $n=5$ animals/group.

\subsection{Effect of Calorie Restriction on Molecular Pathways of Senescence in Hepatic Tissue}

Molecular senescence was investigated by measuring pRb/Rb, Ac-p53, p53, p21 WAF, p16 INK4a, and Sirt-1 protein levels. The livers from the OFCR group displayed a significant decrease in Acp53 $(-49 \% ; p<0.05)$ (Figure 5C,D), p53 (-23\%; $p<0.05)$ (Figure 5E,F), p21 WAF $(-35 \% ; p<0.05)$ (Figure 5I,J), and $\mathrm{p} 16^{\mathrm{INK} 4 \mathrm{a}}(-31 \% ; p<0.05)$ (Figure $\left.5 \mathrm{I}, \mathrm{K}\right)$ protein expression and a significant increase in the protein expression of $\mathrm{pRb} / \mathrm{Rb}(+20 \% ; p<0.05)$ (Figure $5 \mathrm{~A}, \mathrm{~B})$ and Sirt- $1(+24 \% ; p<0.05)$ (Figure $5 \mathrm{G}, \mathrm{H})$.

We observed no significant differences in pRb/Rb (Figure 6A,B, $p>0.05$ ), Ac-p53 (Figure 6C,D, $p>0.05$ ), p53 (Figure 6E,F, $p>0.05$ ), Sirt-1 (Figure 6G,H, $p>0.05$ ), p21 WAF (Figure 6G,I, $p>0.05$ ) or p16 ${ }^{\mathrm{INK} 4 \mathrm{a}}$ (Figure 6G,J, $p>0.05$ ) protein expression in the livers from the NFCR group compared to those in the NF group. 

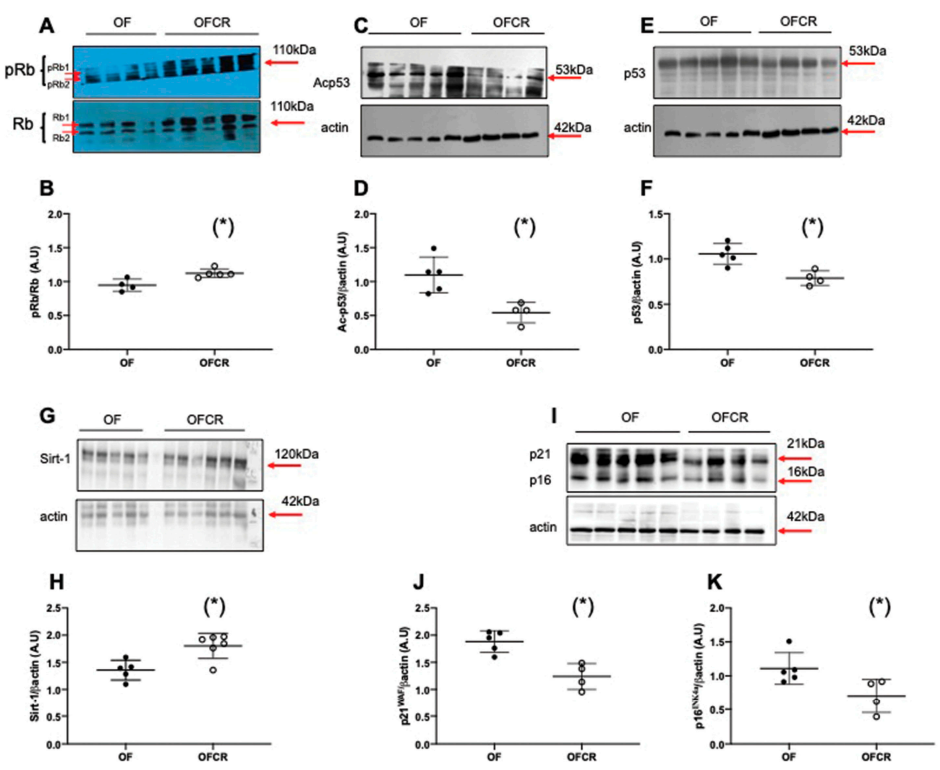

Figure 5. Hepatic senescence in the animals in the OF and OFCR groups at seven months. Liver protein levels of pRb/Rb (A,B), Ac-p53 (C,D), p53 (E,F), Sirt-1 (G,H), p21 WAF $(\mathbf{I}, \mathbf{J})$ and p16 ${ }^{\mathrm{INK} 4 \mathrm{a}}(\mathbf{I}, \mathbf{K})$ were measured by western blot in the OF and OFCR groups. Values are reported as the mean \pm SD; $\left({ }^{*}\right)$ $p<0.05 ; n=5-4$ or 6 animals/group.
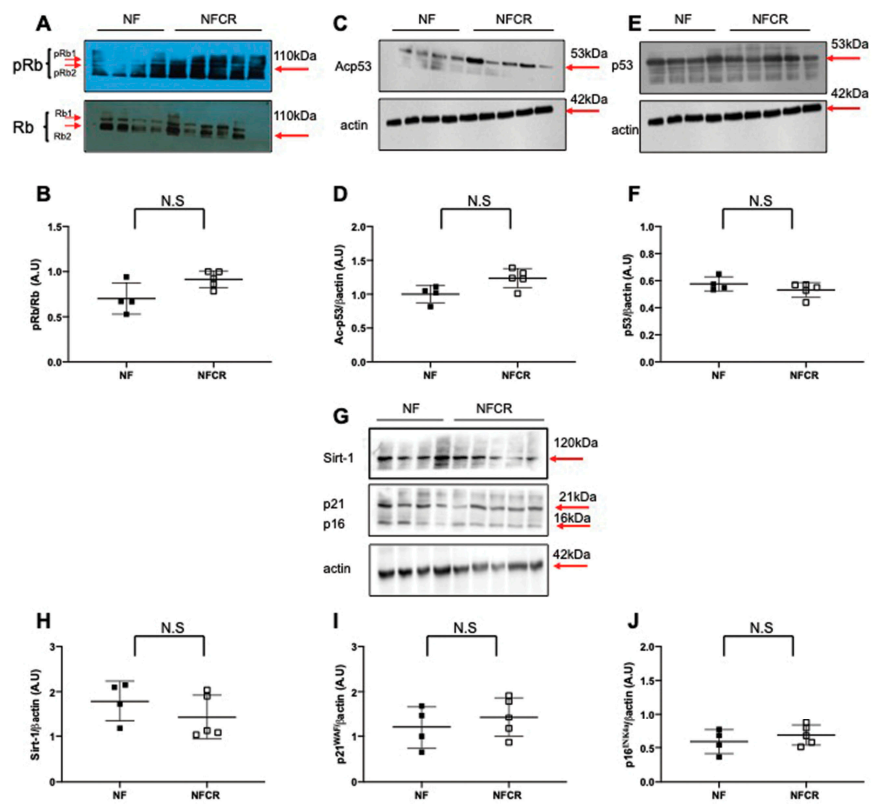

Figure 6. Hepatic senescence in animals in the NF and NFCR groups at seven months. Liver protein levels of p-Rb/Rb (A,B), Ac-p53 (C,D), p53 (E,F), Sirt-1 (G,H), p21 WAF $(\mathbf{G}, \mathbf{I})$ and p16 ${ }^{\mathrm{INK} 4 \mathrm{a}}(\mathbf{G}, \mathbf{J})$ were measured by western blot in the NF and NFCR groups. Values are reported as the mean \pm SD; N.S: nonsignificant, $p>0.05 ; n=5-4$ animals/group).

\section{Discussion}

In this study, moderate CR in adulthood reversed microsteatosis, liver OS, and SIPS induced by transient postnatal $\mathrm{OF}$ in mice.

We explored the effects of $\mathrm{CR}$ on hepatic structure, particularly on liver microsteatosis and fibrosis induced by transient postnatal OF. Using H/E staining, we observed, as shown in Figure 1A, that $\mathrm{CR}$ only in the livers from 7-months-old mice reduces hepatic microsteatosis with decreased in wispy cleared cytoplasm characterized by ballooned cells, as previously observed in $\mathrm{db} / \mathrm{db}$ mice [18] . 
Hepatic steatosis is a feature related to obesity [25] and impaired insulin sensitivity [26]. Therefore, this reduction of microsteatosis by CR could be the consequence of decreased body weight and improved insulin sensitivity and glucose tolerance, as observed previously by $\mathrm{Li}$ et al. in the same animal model that we used in this study [11]. Furthermore, we observed in the livers of 7-month-old OF mice that $\mathrm{CR}$ did not significantly decrease collagen accumulation, identified by Masson's Trichrome staining, or alpha-SMA protein expression, as shown in Figure 1B,D, so CR demonstrated no significant effect on hepatic fibrosis, which is contrary to the findings of other studies [18]. This difference may be due to the moderate (20\%) and shorter (one month) CR used in our study. In addition, hepatic fibrosis is commonly considered an irreversible scarring of liver tissue with an excessive presence of extracellular matrix. CR had no effect on hepatic structure in the NF group.

The liver is particularly sensitive to OS-related damage, which can lead to the development of hepatic disorders. Increased liver reactive oxygen species (ROS) production can occur due to an imbalance between an increased production of ROS and a decreased level of antioxidant defenses, especially ROS scavengers. CR is among the therapies proposed to decrease OS $[27,28]$. We observed in the livers of 7-month-old OF mice that CR decreased superoxide anion levels, as shown in Figure 2A, and increased catalase and, particularly, $\mathrm{Cu} / \mathrm{Zn}$ Sod protein expression, as shown in Figure 2E,C, respectively. It has been shown that $\mathrm{CR}$ improves lifespan via $\mathrm{H}_{2} \mathrm{O}_{2}$ production and by increasing the activity and expression of $\mathrm{Cu} / \mathrm{Zn}$ Sod $[29,30]$. These results suggest that $\mathrm{CR}$ decreased the liver OS induced by transient postnatal OF by improving endogenous antioxidant defense capability. Similar results have been described in regard to livers from rats exposed to dietary restriction ( $40 \%$ restriction of energy intake) [31]. In the NF group, we observed no effects of CR on superoxide anion production, as shown in Figure 2A, or $\mathrm{Cu} / \mathrm{Zn}$ Sod or catalase protein expression, as shown in Figure 2G,I, respectively.

Increased ROS production can induce DNA damage [32]. The protein 53BP-1 is implicated in double-strand break repair, and the levels of 53BP-1 are elevated in many DNA damage response conditions [33]. CR can increase the level of repair of damaged macromolecules [34]. However, CR had no significant effect on 53BP-1 staining in the livers of 7-month-old OF mice, as shown in Figure 3, suggesting that in our animal model, CR could not repair the DNA double-strand breaks induced by postnatal OF. A possible explanation is that the repair of the DNA damage induced by OS (increased superoxide anion production and decreased catalase and $\mathrm{Cu} / \mathrm{Zn}$ superoxide dismutase protein expression) would be lower in calorie-restricted animals due to the lower rates of free radical attack on DNA [35]. CR had no effect on 53BP-1 staining in the NF group in Figure 3.

The accumulation of molecular oxidative damage in various components of the cell that can alter physiological functions is in agreement with the "Oxidative Stress Theory of Aging" [36]. Cellular senescence, which is defined as a sustained antiproliferative response arresting the cell cycle, has been related to increased ROS levels and DNA double-strand breaks [13,37,38]. CR can slow down the aging process [39]. We evaluated the effect of CR on cellular senescence using the detection of lipofuscin, which is an aggregate of oxidized proteins that accumulate progressively, mostly in aged postmitotic cells [40]. Lipofuscin has been identified as a cellular senescence biomarker, particularly a marker of SIPS. We detected lipofuscin accumulation using SBB, Fontana Masson, and d-PAS-resistant staining. We also measured the protein expression of several factors associated with senescence, such as p53, p21 ${ }^{\mathrm{WAF}}, \mathrm{p} 16^{\mathrm{INK} 4 \mathrm{a}}$, and retinoblastoma $(\mathrm{Rb})$ phosphorylation. Among these factors, the induction of $\mathrm{p} 16^{\mathrm{INK} 4 \mathrm{a}}$ and $\mathrm{p} 53$ expression appears to be associated with premature senescence [41]. We observed in the livers from 7-month-old OF mice that CR decreased d-PAS (Figure 4A), SBB (Figure 4C), and Fontana Masson (Figure 4E) staining. Therefore, CR reversed lipofuscin accumulation induced by transient postnatal OF. Moreover, we observed that CR decreased p53, p2 $1^{\mathrm{WAF}}$, and p16 $6^{\mathrm{INK} 4 \mathrm{a}}$ and increased $\mathrm{pRb} / \mathrm{Rb}$ expression in the livers of 7-month-old $\mathrm{OF}$ mice, and these expression levels were up- and downregulated, respectively, by transient postnatal OF (Figure 5). In other models of CR in mice, decreased liver histological senescence biomarkers and $\mathrm{p} 16^{\mathrm{INK} 4 \mathrm{a}}$ expression have also been reported [42,43]. We observed no effect of CR in the NF group on lipofuscin staining (Figure 4) or on $\mathrm{p} 53, \mathrm{p} 21^{\mathrm{WAF}}, \mathrm{p} 16^{\mathrm{INK} 4 \mathrm{a}}$ or $\mathrm{pRb} / \mathrm{Rb}$ protein expression (Figure 6). 
Additionally, a family of deacylase proteins, the sirtuins, has been identified as regulating the senescence process [44]. In particular, Sirt-1 is a nutrient sensor that regulates the expression of several genes involved notably in stress tolerance by modulating antioxidant defenses [45], fat metabolism, and the regulation of longevity [46]; notably these modulations occur due to its modulation by CR [47]. Moreover, a relationship has been observed among CR, Sirt-1, p16 ${ }^{\mathrm{INK} 4 \mathrm{a}}$, and senescence. In human cells, Sirt-1, due to its activation by CR, directly binds to the $\mathrm{p} 16^{\mathrm{INK} 4 \mathrm{a}}$ promoter, which decreases its expression through a deacylation effect of Sirt- 1 and contributes to delaying the aging process and therefore to extending lifespan [48]. We observed in the livers of 7-month-old OF mice that CR improved Sirt-1 protein expression (Figure 5G) and activity by decreasing the acylation of p53 at Lys-379 (Figure 5C), which could explain the higher catalase and $\mathrm{Cu} / \mathrm{Zn}$ Sod protein expression, leading to the reduction in the liver superoxide anion levels, as observed in Figure 2. Additionally, increased expression and restored deacylase activity of Sirt- 1 induced by CR could also explain the reduction of hepatic microsteatosis and obesity induced by transient postnatal OF. In fact, overexpression of Sirt- 1 in mice exposed to a high-fat diet provided protection against hepatic steatosis $[49,50]$ and obesity $[51,52]$. We observed no effect of CR on Sirt-1 protein expression in the NF group, as shown in Figure 6G.

This study has some limitations. The animals were studied on the last day of CR; therefore, the persistence of the beneficial effects induced by $\mathrm{CR}$ when mice once again received an ad libitum diet is unknown. No serum/plasma samples were available to measure the ALAT and ASAT expression as well as pro-inflammatory cytokines. Only males were included in this study, and the characterization of an eventual sexual dimorphism will need further investigation. Further studies are required to identify early biomarkers of these hepatic disorders, notably using epigenetic tools such as DNA methylation and miRNAs.

\section{Conclusions}

In conclusion, this study demonstrates that moderate CR in adulthood reduces liver microsteatosis, OS, and SIPS induced by transient postnatal OF during the lactation period (Figure 7). Therefore, even late CR can confer a protective effect against liver disease. This study also demonstrates that an appropriate eating behavior in adulthood can reduce the long-term effects of altered early nutrition.

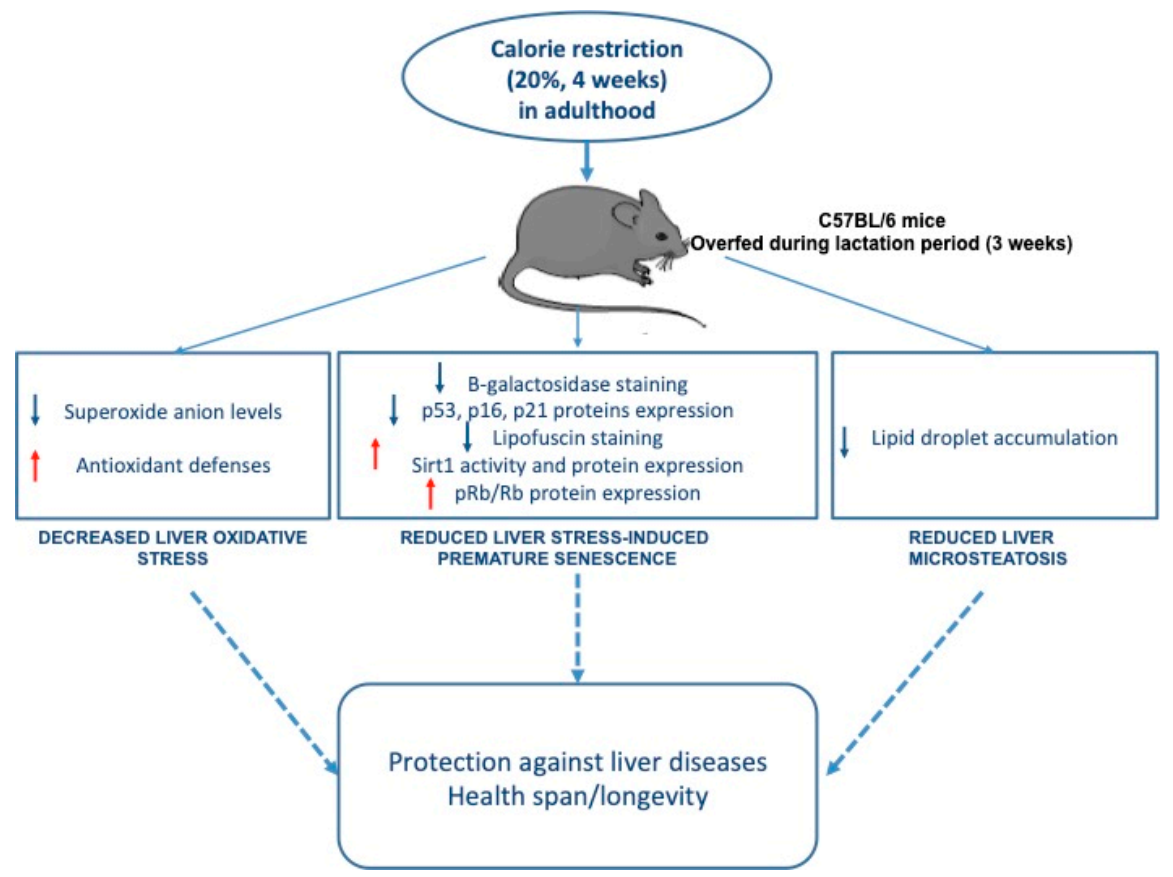

Figure 7. The effects of moderate calorie restriction in adulthood on liver dysfunction induced by transient postnatal overfeeding in C57BL/6 mice. 
Author Contributions: Conceptualization, C.V., U.S. and C.Y.; methodology, C.Y., C.V. and U.S.; software, does not apply; validation, C.Y., N.L., E.R., J.B.A., H.C., D.M., T.R., A.K., E.O., B.S., C.J., C.V. and U.S.; formal analysis, C.Y., D.M. and C.V.; investigation, C.Y., N.L., E.R., D.M., T.R., A.K., E.O. and C.J.; data curation, C.Y.; writing-original draft preparation, C.Y., C.V. and U.S.; writing-review and editing, C.Y., N.L., E.R., J.B.A., H.C., D.M., T.R., A.K., E.O., B.S., C.J., C.V. and U.S.; visualization, C.Y., C.V. and U.S.; supervision, C.V. and U.S.; project administration, U.S.; and funding acquisition, C.V., U.S.

Funding: This work was supported by grants from the French Ministry of Research and the Institut National de la Santé et de la Recherche Médicale (INSERM, France) for the generation of the animal model and by CHUV (No: 30034)-University of Lausanne (Switzerland) and the W. and E. Grand d'Hauteville Foundation For Academic Biomedical and Nursing Research (Lausanne, Switzerland) for laboratory analyses on the hepatic tissue.

Acknowledgments: The authors gratefully thank the Mouse Pathology Institute, Christine Sempoux, Anne Christine Peyter, Mohamed Benahmed and Pedrazzini' laboratory for the provided technical assistance.

Conflicts of Interest: The authors declare no conflict of interest.

\section{Abbreviations}

$\alpha$-SMA: alpha smooth muscle actin; CR: calorie restriction; $\mathrm{Cu} / \mathrm{Zn}$ Sod: $\mathrm{Cu} / \mathrm{Zn}$ superoxide dismutase; d-PAS: diastase periodic acid Schiff; H/E: hematoxylin/eosin; MetS: metabolic syndrome; NAFLD: nonalcoholic fatty liver disease; NF: normal feeding; NFCR: normal feeding calorie restriction; OF: overfeeding; OFCR: overfeeding calorie restriction; OS: oxidative stress; SBB: Sudan black B; SD: standard deviation; SIPS: stress-induced premature senescence; Sirt-1: sirtuin-1; (p)Rb: (phospho) retinoblastoma tumor suppressor.

\section{References}

1. NCD Risk Factor Collaboration (NCD-RisC). Worldwide trends in body-mass index, underweight, overweight, and obesity from 1975 to 2016: A pooled analysis of 2416 population-based measurement studies in 128.9 million children, adolescents, and adults. Lancet 2017, 390, 2627-2642. [CrossRef]

2. Duque-Guimaraes, D.E.; Ozanne, S.E. Nutritional programming of insulin resistance: Causes and consequences. Trends Endocrinol. Metab. 2013, 24, 525-535. [CrossRef]

3. Vernon, G.; Baranova, A.; Younossi, Z.M. Systematic review: The epidemiology and natural history of non-alcoholic fatty liver disease and non-alcoholic steatohepatitis in adults. Aliment. Pharmacol. Ther. 2011, 34, 274-285. [CrossRef] [PubMed]

4. Bellentani, S. The epidemiology of non-alcoholic fatty liver disease. Liver Int. 2017, 37 (Suppl. 1), 81-84. [CrossRef] [PubMed]

5. Cunha, A.C.; Pereira, R.O.; Pereira, M.J.; Soares Vde, M.; Martins, M.R.; Teixeira, M.T.; Souza, E.P.; Moura, A.S. Long-term effects of overfeeding during lactation on insulin secretion-The role of glut-2. J. Nutr. Biochem. 2009, 20, 435-442. [CrossRef] [PubMed]

6. You, S.; Gotz, F.; Rohde, W.; Dorner, G. Early postnatal overfeeding and diabetes susceptibility. Exp. Clin. Endocrinol. 1990, 96, 301-306. [CrossRef]

7. Plagemann, A.; Heidrich, I.; Gotz, F.; Rohde, W.; Dorner, G. Obesity and enhanced diabetes and cardiovascular risk in adult rats due to early postnatal overfeeding. Exp. Clin. Endocrinol. 1992, 99, 154-158. [CrossRef]

8. Rodrigues, A.L.; De Souza, E.P.; Da Silva, S.V.; Rodrigues, D.S.; Nascimento, A.B.; Barja-Fidalgo, C.; De Freitas, M.S. Low expression of insulin signaling molecules impairs glucose uptake in adipocytes after early overnutrition. J. Endocrinol. 2007, 195, 485-494. [CrossRef]

9. Habbout, A.; Li, N.; Rochette, L.; Vergely, C. Postnatal overfeeding in rodents by litter size reduction induces major short- and long-term pathophysiological consequences. J. Nutr. 2013, 143, 553-562. [CrossRef]

10. Habbout, A.; Delemasure, S.; Goirand, F.; Guilland, J.C.; Chabod, F.; Sediki, M.; Rochette, L.; Vergely, C. Postnatal overfeeding in rats leads to moderate overweight and to cardiometabolic and oxidative alterations in adulthood. Biochimie 2012, 94, 117-124. [CrossRef]

11. Li, N.; Guenancia, C.; Rigal, E.; Hachet, O.; Chollet, P.; Desmoulins, L.; Leloup, C.; Rochette, L.; Vergely, C. Short-term moderate diet restriction in adulthood can reverse oxidative, cardiovascular and metabolic alterations induced by postnatal overfeeding in mice. Sci. Rep. 2016, 6, 30817. [CrossRef] [PubMed]

12. Li, S.; Tan, H.Y.; Wang, N.; Zhang, Z.J.; Lao, L.; Wong, C.W.; Feng, Y. The role of oxidative stress and antioxidants in liver diseases. Int. J. Mol. Sci. 2015, 16, 26087-26124. [CrossRef] 
13. Yzydorczyk, C.; Li, N.; Chehade, H.; Mosig, D.; Bidho, M.; Keshavjee, B.; Armengaud, J.B.; Nardou, K.; Siddeek, B.; Benahmed, M.; et al. Transient postnatal overfeeding causes liver stress-induced premature senescence in adult mice. Sci. Rep. 2017, 7, 12911. [CrossRef] [PubMed]

14. Yu, H.; Jia, W.; Guo, Z. Reducing liver fat by low carbohydrate caloric restriction targets hepatic glucose production in non-diabetic obese adults with non-alcoholic fatty liver disease. J. Clin. Med. 2014, 3, 1050-1063. [CrossRef] [PubMed]

15. Kirk, E.; Reeds, D.N.; Finck, B.N.; Mayurranjan, S.M.; Patterson, B.W.; Klein, S. Dietary fat and carbohydrates differentially alter insulin sensitivity during caloric restriction. Gastroenterology 2009, 136, 1552-1560. [CrossRef]

16. Anderson, R.M.; Weindruch, R. The caloric restriction paradigm: Implications for healthy human aging. Am. J. Hum. Biol. 2012, 24, 101-106. [CrossRef] [PubMed]

17. Bales, C.W.; Kraus, W.E. Caloric restriction: Implications for human cardiometabolic health. J. Cardiopulm. Rehabil. Prev. 2013, 33, 201-208. [CrossRef]

18. Kim, K.E.; Jung, Y.; Min, S.; Nam, M.; Heo, R.W.; Jeon, B.T.; Song, D.H.; Yi, C.O.; Jeong, E.A.; Kim, H.; et al. Caloric restriction of $\mathrm{db} / \mathrm{db}$ mice reverts hepatic steatosis and body weight with divergent hepatic metabolism. Sci. Rep. 2016, 6, 30111. [CrossRef]

19. Rusli, F.; Boekschoten, M.V.; Zubia, A.A.; Lute, C.; Muller, M.; Steegenga, W.T. A weekly alternating diet between caloric restriction and medium fat protects the liver from fatty liver development in middle-aged c57bl/6j mice. Mol. Nutr. Food Res. 2015, 59, 533-543. [CrossRef]

20. Guarente, L. Calorie restriction and sirtuins revisited. Genes Dev. 2013, 27, 2072-2085. [CrossRef]

21. Sinclair, D.A. Toward a unified theory of caloric restriction and longevity regulation. Mech. Ageing Dev. 2005, 126, 987-1002. [CrossRef] [PubMed]

22. Juif, J.G.; Langer, B. Maladies Endocriniennes Néonatales. In Médecine Néonatale et Fœtale; Haddad, J., Langer, B., Eds.; Springer: Paris, France, 2004; pp. 515-520.

23. Yzydorczyk, C.; Comte, B.; Cambonie, G.; Lavoie, J.C.; Germain, N.; Ting Shun, Y.; Wolff, J.; Deschepper, C.; Touyz, R.M.; Lelievre-Pegorier, M.; et al. Neonatal oxygen exposure in rats leads to cardiovascular and renal alterations in adulthood. Hypertension 2008, 52, 889-895. [CrossRef] [PubMed]

24. Georgakopoulou, E.A.; Tsimaratou, K.; Evangelou, K.; Fernandez Marcos, P.J.; Zoumpourlis, V.; Trougakos, I.P.; Kletsas, D.; Bartek, J.; Serrano, M.; Gorgoulis, V.G. Specific lipofuscin staining as a novel biomarker to detect replicative and stress-induced senescence. A method applicable in cryo-preserved and archival tissues. Aging 2013, 5, 37-50. [CrossRef] [PubMed]

25. Watanabe, S.; Yaginuma, R.; Ikejima, K.; Miyazaki, A. Liver diseases and metabolic syndrome. J. Gastroenterol. 2008, 43, 509-518. [CrossRef] [PubMed]

26. Alam, S.; Mustafa, G.; Alam, M.; Ahmad, N. Insulin resistance in development and progression of nonalcoholic fatty liver disease. World J. Gastrointest. Pathophysiol. 2016, 7, 211-217. [CrossRef]

27. Sohal, R.S.; Weindruch, R. Oxidative stress, caloric restriction, and aging. Science 1996, 273, 59-63. [CrossRef]

28. Stankovic, M.; Mladenovic, D.; Ninkovic, M.; Vucevic, D.; Tomasevic, T.; Radosavljevic, T. Effects of caloric restriction on oxidative stress parameters. Gen. Physiol. Biophys. 2013, 32, 277-283. [CrossRef]

29. Mesquita, A.; Weinberger, M.; Silva, A.; Sampaio-Marques, B.; Almeida, B.; Leao, C.; Costa, V.; Rodrigues, F.; Burhans, W.C.; Ludovico, P. Caloric restriction or catalase inactivation extends yeast chronological lifespan by inducing h2o2 and superoxide dismutase activity. Proc. Natl. Acad. Sci. USA 2010, 107, 15123-15128. [CrossRef]

30. Mura, C.V.; Gong, X.; Taylor, A.; Villalobos-Molina, R.; Scrofano, M.M. Effects of calorie restriction and aging on the expression of antioxidant enzymes and ubiquitin in the liver of emory mice. Mech. Ageing Dev. 1996, 91, 115-129. [CrossRef]

31. Chen, L.H.; SaxonKelley, D.M.; Snyder, D.L. Effects of age and dietary restriction on liver endogenous antioxidant defenses in male lobund-wistar rats. Age 1996, 19, 101-109. [CrossRef]

32. Yzydorczyk, C.; Mitanchez, D.; Buffat, C.; Ligi, I.; Grandvuillemin, I.; Boubred, F.; Simeoni, U. [oxidative stress after preterm birth: Origins, biomarkers, and possible therapeutic approaches]. Arch. Pediatr. 2015, 22, 1047-1055. [CrossRef] [PubMed]

33. Joo, W.S.; Jeffrey, P.D.; Cantor, S.B.; Finnin, M.S.; Livingston, D.M.; Pavletich, N.P. Structure of the 53bp1 brct region bound to 553 and its comparison to the brca1 brct structure. Genes Dev. 2002, 16, 583-593. [CrossRef] [PubMed] 
34. Stuart, J.A.; Karahalil, B.; Hogue, B.A.; Souza-Pinto, N.C.; Bohr, V.A. Mitochondrial and nuclear DNA base excision repair are affected differently by caloric restriction. FASEB J. 2004, 18, 595-597. [CrossRef] [PubMed]

35. Barja, G. The flux of free radical attack through mitochondrial DNA is related to aging rate. Aging 2000, 12, 342-355. [CrossRef]

36. Bokov, A.; Chaudhuri, A.; Richardson, A. The role of oxidative damage and stress in aging. Mech. Ageing Dev. 2004, 125, 811-826. [CrossRef]

37. Passos, J.F.; Nelson, G.; Wang, C.; Richter, T.; Simillion, C.; Proctor, C.J.; Miwa, S.; Olijslagers, S.; Hallinan, J.; Wipat, A.; et al. Feedback between p21 and reactive oxygen production is necessary for cell senescence. Mol. Syst. Biol. 2010, 6, 347. [CrossRef]

38. Davalli, P.; Mitic, T.; Caporali, A.; Lauriola, A.; D'Arca, D. Ros, cell senescence, and novel molecular mechanisms in aging and age-related diseases. Oxid. Med. Cell Longev. 2016, 2016, 3565127. [CrossRef]

39. Martin, B.; Mattson, M.P.; Maudsley, S. Caloric restriction and intermittent fasting: Two potential diets for successful brain aging. Ageing Res. Rev. 2006, 5, 332-353. [CrossRef]

40. Jung, T.; Bader, N.; Grune, T. Lipofuscin: Formation, distribution, and metabolic consequences. Ann. N. Y. Acad. Sci. 2007, 1119, 97-111. [CrossRef]

41. Huschtscha, L.I.; Reddel, R.R. P16 (ink4a) and the control of cellular proliferative life span. Carcinogenesis 1999, 20, 921-926. [CrossRef]

42. Krishnamurthy, J.; Torrice, C.; Ramsey, M.R.; Kovalev, G.I.; Al-Regaiey, K.; Su, L.; Sharpless, N.E. Ink4a/arf expression is a biomarker of aging. J. Clin. Investig. 2004, 114, 1299-1307. [CrossRef] [PubMed]

43. Wang, C.; Maddick, M.; Miwa, S.; Jurk, D.; Czapiewski, R.; Saretzki, G.; Langie, S.A.; Godschalk, R.W.; Cameron, K.; von Zglinicki, T. Adult-onset, short-term dietary restriction reduces cell senescence in mice. Aging 2010, 2, 555-566. [CrossRef] [PubMed]

44. Vassallo, P.F.; Simoncini, S.; Ligi, I.; Chateau, A.L.; Bachelier, R.; Robert, S.; Morere, J.; Fernandez, S.; Guillet, B.; Marcelli, M.; et al. Accelerated senescence of cord blood endothelial progenitor cells in premature neonates is driven by sirt1 decreased expression. Blood 2014, 123, 2116-2126. [CrossRef] [PubMed]

45. Olmos, Y.; Sanchez-Gomez, F.J.; Wild, B.; Garcia-Quintans, N.; Cabezudo, S.; Lamas, S.; Monsalve, M. Sirt1 regulation of antioxidant genes is dependent on the formation of a foxo3a/pgc-1alpha complex. Antioxid. Redox Signal. 2013, 19, 1507-1521. [CrossRef] [PubMed]

46. Leibiger, I.B.; Berggren, P.O. Sirt1: A metabolic master switch that modulates lifespan. Nat. Med. 2006, 12, 34-36. [CrossRef] [PubMed]

47. Cohen, H.Y.; Miller, C.; Bitterman, K.J.; Wall, N.R.; Hekking, B.; Kessler, B.; Howitz, K.T.; Gorospe, M.; de Cabo, R.; Sinclair, D.A. Calorie restriction promotes mammalian cell survival by inducing the sirt1 deacetylase. Science 2004, 305, 390-392. [CrossRef] [PubMed]

48. Li, Y.; Tollefsbol, T.O. P16 (ink4a) suppression by glucose restriction contributes to human cellular lifespan extension through sirt1-mediated epigenetic and genetic mechanisms. PLoS ONE 2011, 6, e17421.

49. Colak, Y.; Yesil, A.; Mutlu, H.H.; Caklili, O.T.; Ulasoglu, C.; Senates, E.; Takir, M.; Kostek, O.; Yilmaz, Y.; Yilmaz Enc, F.; et al. A potential treatment of non-alcoholic fatty liver disease with sirt1 activators. J. Gastrointest. Liver Dis. 2014, 23, 311-319.

50. Tobita, T.; Guzman-Lepe, J.; Takeishi, K.; Nakao, T.; Wang, Y.; Meng, F.; Deng, C.X.; Collin de l’Hortet, A.; Soto-Gutierrez, A. Sirt1 disruption in human fetal hepatocytes leads to increased accumulation of glucose and lipids. PLoS ONE 2016, 11, e0149344. [CrossRef]

51. Kurylowicz, A.; Owczarz, M.; Polosak, J.; Jonas, M.I.; Lisik, W.; Jonas, M.; Chmura, A.; Puzianowska-Kuznicka, M. Sirt1 and sirt7 expression in adipose tissues of obese and normal-weight individuals is regulated by micrornas but not by methylation status. Int. J. Obes. 2016, 40, 1635-1642. [CrossRef]

52. Zhu, Y.; Huang, J.J.; Zhang, X.X.; Yan, Y.; Yin, X.W.; Ping, G.; Jiang, W.M. Qing gan zi shen tang alleviates adipose tissue dysfunction with up-regulation of sirt1 in spontaneously hypertensive rat. Biomed. Pharmacother. 2018, 105, 246-255. [CrossRef] [PubMed]

(C) 2019 by the authors. Licensee MDPI, Basel, Switzerland. This article is an open access article distributed under the terms and conditions of the Creative Commons Attribution (CC BY) license (http://creativecommons.org/licenses/by/4.0/). 